\title{
Flax Seed
}

\author{
Hayriye Alp
}

Necmettin Erbakan University, GETAT CENTER, Konya, Turkey.

Corresponding Author: Hayriye Alp, Necmettin Erbakan University, GETAT CENTER, Konya, Turkey.

Received date: August 19, 2021; Accepted date: August 28, 2021; Published date: September 07, 2021

Citation: Hayriye Alp (2021), Flax Seed. J. Gastroenterology Pancreatology and Hepatobilary Disorders. 5(5) DOI: 10.31579/2641-5194/045

Copyright: (c) 2021, Hayriye Alp, This is an open access article distributed under the Creative Commons Attribution License, which permits unrestricted use, distribution, and reproduction in any medium, provided the original work is properly cited.

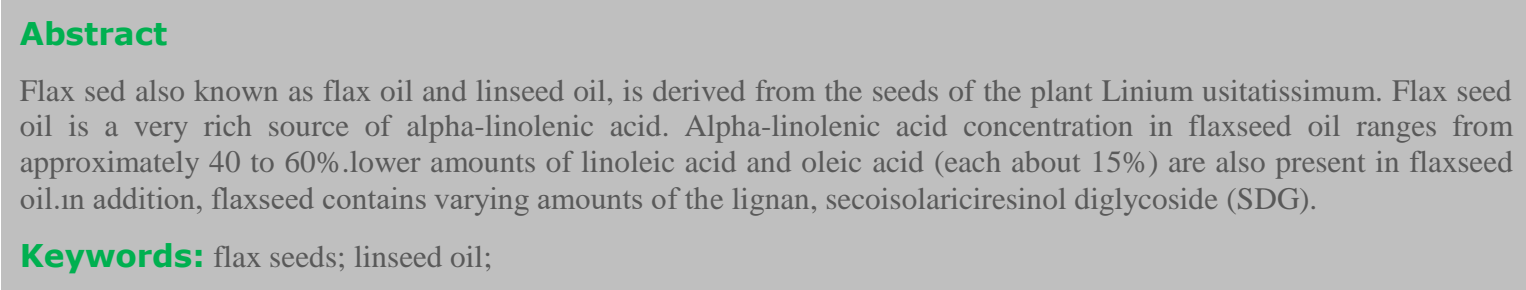

\section{Introduction}

Alpha-linolenic acid (ala) is an n-3(omega-3), all-cis polyunsaturated fatty acid containing 18 carbon atoms and three double bonds.It is also known as ALA;ALA, 18:3n-3;9,12,15- octadecatrienoic acid.ALA has the following structural Formula:

\section{$\mathrm{H} 3 \mathrm{C}(\mathrm{CH} 2) 6 \mathrm{COOH}$}

ALA is present in flaxseed oil in the form of a triglyceride.The Mediterranean diet high in ALA, appears to lower the risk of coronary artery disease and certain types of cancer.

The lignan SDG belongs to a group of plant substances known as phytoestrogens. See also flaxseed lignans and secoisolariciresinol diglycoside(sdg).

\section{Actıons and pharmacology}

Act1oons flaxseed oil may be have anti-inflammatory, anti-atherogenic, anti-thrombotic and anti-proliferative activities.

\section{Mechanism of actıon}

ALA is metabolized to eicosopentaenoic acid (EPA). EPA is a precursor of the series- 3 prostaglandins, the series- 5 leukotriens and the series- 3 thromboxanes. These eicosanoids have anti-inflammatory and antiatherogenic properties.ALA metabolites may also inhibit the productionof the pro-inflammatory eicosanoids, prostaglandin E2 (PGE2), and leukotriene B4 (LT-B4), as well as the pro-inflammatory cytokines, tumor necrosis factor-alpha (TNF- $\alpha$ ) and interleukin-1 beta(IL$\beta)$. Incorporation of ALA and its metabolites in cell membranes can affect membrane fluidity and may play a role in anti-inflammotory activitiy, inhibition of platelet aggregation and possibly in anti-proliferative actions of ALA.

Secoisolaricoresinol diglycoside (SDG) is metabolized to enterolactone and enterodiol.These substances may have anti-platelet-activating factor activity, which would produce anti-thrombotic activity.SDG metabolites may also block some of the cancer-inducing effects of estrogen and may have selective estrogen receptor modulating(SERM) activity.

\section{Pharmacokinetics}

ALA-laden triglycerides in flaxseed oil are absorbed from the small intestine aided by bile salts. During this process, there is some deaclyation of the fatty acids of the triglycerides. Reaclylation takes place within the mucosal cells of the small intestine, and the ALA-laden triglycerides enter yhe lymph system in the form of chylomicrons. ALA-laden chylomicrons are transported from the lymph into blood, where ALA is then crried in various lipid particles to the various cells of the body, where it gets metabolized to EPA and series-3 prostaglandins, the series-5 leukotriens and the series- 3 thromboxanes.

The flaxseed oil lignan SDG is metabolized by bacteria in the colon to enterolactone and enterodiol.These substances are absorbed from the colon and metabolized to several hydroxylated metabolites in the body.

\section{Indications and usage}

Flaxseed and flaxseed oil may be indicated in hyperlipidemia to decresea platelet aggregation, to lower blood pressure, to help prevent heart attacks and stroke, and to ameliorate some of the symptoms of arthritis. There is a suggestion that it may be helpful in the some cancers.Claims that it can be useful in the treatment of anxiety, constipation, vaginitis and weight los are unsubstantiated.

\section{Research summary}

Though high in alpha-linolenic acid(ALA), Flaxseed and flaxseed oil may have beneficial effects that may sometimes be independent of their ALA content. In animal models, flaxseed-enriched diets have significantly reduced hypercholestemic atherosclerosis: this has been true even when CDC-Flaxseed (type 2flaxseed) which contains quantities of oil and lignan similar to that of Standard flaxseed but with very little ALA 
content, has been used.lignan content could be responsible for some of the positive effects.Lignans have been shown in the various studies, to contain anti-platelet-activating factor activity and posses antioksidant properties.

Development of atherosclorosis has been reduced by up to $69 \%$ in some of these studies using flaxseed -enriched diets.

To what extent research findings using flaxseed itself can be extended to the use of flaxseed oil remains to be determine.There is preliminary clicical evidence suggesting that the oil can decrease platelet aggregation, that it may lower cholestel(but probably not triglycerides) and that it might have some ability to lower blood pressure and have some antiinflammatory effects in some with arthritis.

Some animal studies studies have suggested a possible role for flaxseed in the treatment of some cancers, particularly mammary cancers. Lignans have been shown to block some of the cancer-inducing effects of endogenous estrogens.human trials are underway.

Recently some poultry farmers have begun feding chickens diets rich in flaxseed boosting the omega-3 fatty acid content of the eggs of these chickens to levels eight to 10 times that of regular eggs.these functional foods have already captured four percent of the Canadian egg market.1t has been reported that two of these eggs supply half of Health Canada's recommended daily intake of omega-3 fatty acids for adults.

A researcher at he Center for genetics, nutrition and health, Washington, DC. Has concluded:' The availability of omega-3 fatty acid-enriched products should lead to improvement in the food supply. Studies with omega-3 enriched eggs lower cholesterol levels, platelet aggregation and blood pressure'

Claims that flaxseed and flaxseed oil are useful in the treating anxiety, vaginitis and weight loss are not substantiated by the available research data.veterians reportedly use these products to treat some animals for constipation, but human data are lacking.and regarding animals, flaxseed oil fed to broiler chickens has been found to reduce pulmonary hypertension and right ventricular hypertrophy in birdsraised under hypoxic conditions.no human data are avalaible.

\section{Contraindications}

Flaxseed oil is contraindicated in those who are hypersensivite to any component of a flaxseed oil-containing product.

\section{Precautions}

Infants, young children, pregnant women and nursing mothers should avoid supplemental flaxseed oil pending long-term safety studies. Because of possible antithrombotic activity, those with hemophilia and those taking warfarin should be cautious about the use of supplemental flaxseed or flaxseed oil.flaxseed oil intake should be halted in those having surgical procedures.

\section{Adverse reactions}

Flaxseed oil may cause mild gastrointestinal symptoms, such as diarrhea.

\section{Interactions}

Interactions may ocur between flaxseed oil-ALA and its metabolites and warfarin, asprin and NSAIDs.such interactions, if they were to ocur , might be manifested by nosebleeds and increased susceptibility to bruising.1f this does ocur, consideration should be given to lowering or stopping intake.

Interactions may ocur if flaxseed oil is used with other nutritional supplements, such as fish oils, which have antitrombotic avtivity.
Interactions may ocur between ALA and its metabolites with such herbs as garlic(Allium Sativa) and ginko(Ginkgo biloba) such interactions might be manifested by nosebleeds and easy bruising.

\section{Over dosage}

There are no reports of flaxseed oil overdosage.

\section{Dosage}

Flaxseed oil comes in few forms:capsules containing from 40-60 percent ALA, oils and in functional foods.regarding the latter, ALA-laden eggs are available from laying hens fed flaxseed diets.

Three to four grams of ALA is approximately equivalent to the 0.3 grams of EPA which one would derive from a fish-rich diet.six 1 gram capsules of flaxseed oil that are 50\% ALA-containing flaxseed oil provides about 7.5 grams of ALA.many use flaxseed oil component in salad dressing. Since flaxseed oil easily oxidized, it is important that it contains an antioksidant, such as vitamin E.the amount of flaxseed ligna in flaxseed oil are highly variable.

\section{References}

1. Alman MA Penna M, Pang D. (1999) Supplementation with flaxseed oil versus sunflower seed oil healty young menconsuming a low fat diet:effects on platelet composition and function. Eur J Clin Nutr. 49:169-178.

2. Fisher S Honigmann G Hora C et al. (1984) Results of linseed oil and olive oil therapy in hyperlipoproteinemia patients. Dtsch Z Verdau Stoffwechselkr. 44:245-251

3. Indu M Ghafoorunissa. (1992) N- 3fatty acids in Indian diets:comparison of the effects of precursor(alpha-linolenic acid) vs. product (long-chain n-3 polyunsaturated fatty acids) nutr.Resp. 12:569-582

4. James MJ Gibson RA Cleland LG. (2000) Dietary polyunsaturated fatty acids and inflammatory mediator production .Am. J Clin Nutr. 71(suppl):343-348.

5. Jeckins DJ Kendall CW Vidgen E et al. (1999) Health aspects of partially defatted flaxseed including effects on serum lipids oxidative measures and ex vivo androgen and progestin activity:a controlled crossover trial. Am J Clin Nutr. 69:395-402.

6. Prasad K. (1997) Dietary flaxseed in prevention of hypercholestrolemic atherosclerosis. Atherosclerosis. 132:6976.

7. Rozanova IA Pogozheva AV Kupakova SN et al. (1997) Effects of anti-atherosclerotic diet,containing polyunsaturated fatty acids of the omega- 3 family from flax oil on fatty acid composition of cell membranes of patients with ischemic heart disease hypertensive disease and hyperlipoproteinemia. Vopr Pitan. 5:15-17.

8. Simopoulus AP. (1999) New products from the agri-food industry:the return of n-3 fatty acids into the food supply. Lipids. 34 suppl:297-301

9. Singer P Wirth M Berg I. (1990) A possible contribution of decrease in free fatty acids to low serum triglyseride after diets supplemented with n-6 and n-3 polyunsaturated fatty acids. Atherosclerosis. 83:167-175.

10. Tou JC Thompson LU. (1999) Exposure to flaxseed or its lignan component during different developmental stages influences rat mamory gland structures. Carsinogenesis. 20:1831-1835.

11. Walton JP Bond jm Julian RJ et al. (1999) Effects of dietary flax oil and hypobaric hypoxia an pulmonary hypertension and haematological variables in broiler chickens. Br Poult sci. 40:385-391. 